\title{
NOTAS SOBRE EL PERJUICIO SEXUAL COMO UN TIPO DE DAÑO MORAL O DAÑO NO PATRIMONIAL CIVILMENTE INDEMNIZABLE. COMENTARIO A LA SENTENCIA DE LA CORTE SUPREMA DE FECHA 30 DE ABRIL DE 2020, DICTADA EN AUTOS ROL 33.598-2018
}

Notes on sexual harm as a type of moral damage or non-patrimonial damage civilly compensable. Comment to the sentence of the Supreme Court dated April 30, 2020, № 33.598-2018

\section{DAVID AlEJANDRO RODRÍGUEZ GUERRA* Universidad Diego Portales}

\begin{abstract}
RESUMEN
Uno de los tipos de daño moral es el perjuicio sexual, cuyo origen puede ser fisiológico en caso de daños a órganos sexuales, o psicológico en caso de delitos sexuales. El primero afectará la capacidad física de mantener relaciones o procrear, mientras que los segundos afectarán su capacidad moral o emocional. Además, el perjuicio sexual tiene incidencia en las obligaciones matrimoniales, puesto que no procrear o no cohabitar no sería una infracción imputable, y así mismo, el perjuicio sexual tiene relevancia en la identificación de víctimas de perjuicio sexual por rebote.
\end{abstract}

PALABRAs CLAVE

Daño moral, perjuicio sexual, relaciones sexuales, procreación, delitos sexuales.

\section{ABSTRACT}

Sexual harm is a type of moral damage, which origin can be physiological in case of damage to sexual organs, or psychological in case of sexual crimes. The first will affect the physic ability to maintain sexual relationships or procreate, while the seconds will affect the moral or emotional ability. Also, the sexual harm has an impact on marital obligations, since not procreating or not cohabiting would not be an imputable infraction, and likewise, sexual harm is relevant to identify victims of sexual harm by rebound.

\section{KEYWORDS}

Moral damage, sexual harm, sexual relationships, procreation, sexual crimes.

\section{Introducción}

Existen diversas discusiones en torno al daño moral. Una de estas es que el concepto mismo es impreciso y equívoco. Se indica aquello, aludiendo a que el daño moral es en realidad un género dentro del cual se encuentran especies de daños morales. Es por esto, que cierta doctrina ha propuesto abandonar el concepto de daño moral y reemplazarlo por el de daño extrapatrimonial. Esto, no por una simple incomodidad conceptual, sino porque la concepción clásica liga el daño moral al denominado "pretium doloris", lo que no sería del todo correcto, toda vez que el pretium doloris es tan solo una de las secuelas no patrimoniales que puede sufrir una víctima, entre otras.

De manera tal, que el daño moral en realidad corresponde a una "categoría de perjuicios" dentro de la cual es posible encontrar otro tipo de secuelas, que se caracterizan por ser, al igual

\footnotetext{
* Abogado. Licenciado en Ciencias Jurídicas y Sociales Universidad Diego Portales. Magíster en Derecho Civil Patrimonial Universidad Diego Portales. Certificado en Derecho Civil Continental Université Paris II Panthéon-Assas. Ayudante Novel del Departamento de Derecho de los Negocios de la Facultad de Derecho de la Universidad Diego Portales, Santiago, Chile. Correo electrónico: david.rodriguezg@mail.udp.cl.
} 
que el pretium doloris, de naturaleza no patrimonial, pero que no se identifican precisamente con él.

Es en este contexto en que surge el concepto de perjuicio sexual, cuya existencia ha sido reconocida por autorizada doctrina y también por la jurisprudencia. El presente trabajo tiene por objeto analizar el concepto de perjuicio sexual e identificar si resulta útil recurrir a él como un tipo de daño no patrimonial.

Para dichos efectos expondré qué se ha dicho en torno al contraste entre daño moral y daño no patrimonial; qué es un perjuicio sexual; y finalmente expondré ciertas aplicaciones prácticas del concepto en torno a las obligaciones matrimoniales y qué sucede en caso de existir un perjuicio sexual por repercusión.

\section{Antecedentes del caso}

Ante el 170 Juzgado Civil de Santiago ${ }^{1}$, la demandante, por sí y en representación de su hijo, interpuso demanda de indemnización de perjuicios por responsabilidad extracontractual por falta de servicio en contra del Hospital Clínico San Borja Arriarán y en contra del Servicio de Salud Metropolitano Central. Relata que, en el año 2011, y en virtud de su tercer embarazo, fue diagnosticada con diabetes gestacional, placenta baja, ITU persistente y macrosomía fetal. La matrona, luego de realizar exámenes físicos, le produjo la rotura del saco amniótico, por lo que fue ingresada a la sala de pre-parto. Indica que por sus antecedentes clínicos era obligatorio realizar una cesárea, sin embargo, el equipo médico optó por el parto vaginal.

Al iniciar el trabajo de parto, se le instruyó que pujara con todas sus fuerzas, desmayándose luego de dar a luz. Al despertar, se le explica que sufrió un desgarro perineal de cuarto grado y que, por el retiro violento de su hijo, se le provocó una deformación en la parte izquierda del cráneo, con posible compromiso neurológico. Indica la demandante, que los desgarros de primer y segundo grado son normales, pero los de tercer y cuarto grado corresponden a negligencia médica.

De acuerdo a su hoja de evolución, se suturó el desgarro en varias oportunidades y fue dada de alta luego de seis días. Sin embargo, con el pasar de los días, comenzó a notar anormalidades, pues hacía sus deposiciones por la vagina y orinaba por el ano. Concurrió de urgencia al hospital San Borja Arriarán donde le indicaron que aquello era lo normal para cualquier parto. Sin embargo, al asistir a control con la matrona del Consultorio San José de Chuchunco, la derivaron de urgencia al hospital San Borja, a la unidad de ginecología y proctología, donde finalmente le diagnosticaron una fístula recto vaginal.

Luego, expone que el recinto hospitalario comenzó el proceso de reparación físico mediante seguidas operaciones, sin embargo, alega que estas no han logrado reparar del todo su daño, ya que, hasta la interposición de la demanda, continuó eliminado heces y gases por la vagina, orina por el ano, y la menstruación por ambos. En lo que interesa, alega haber sufrido un perjuicio sexual, dadas las condiciones en que se encuentran sus genitales, y hace presente que los médicos no han logrado establecer si podrá volver a tener hijos, avaluando dicho daño en $\$ 250.000 .000$.

El Servicio de Salud Metropolitano alegó la falta de legitimación pasiva, puesto que, el Hospital San Borja Arriarán es autogestionado, por lo que tiene patrimonio propio y autonomía, por tanto, no le cabe responsabilidad por actos que se imputan a otro órgano.

Alega, así mismo, la prescripción extintiva de la acción y que no se cumplen los requisitos de la falta de servicio, ya que, no ha existido acción u omisión imputable por parte de los demandados. Indica que la demandante ya había tenido dos partos vaginales anteriores, por lo que no era obligatoria la cesárea, y que la diabetes le fue controlada. Relata, que el desagarro vagino-perineal de cuarto grado fue provocado, posiblemente, por la salida del hombro posterior del recién nacido dado su gran volumen y peso. Indica que la demandada, luego,

${ }^{1} 17$ o Juzgado Civil de Santiago, Rol № C-6224-2016, de 26 de mayo de 2017. 
presentó una fístula recto-vaginal, que es una complicación previsible, pero que fue operada oportunamente, y que no es efectivo que la matrona haya actuado con fuerza. Expone, que no existe causalidad entre los hechos y los daños demandados, y que no es posible imputar antijuricidad a las actuaciones del personal médico, sino que estos fueron eficientes.

El Juzgado de Letras, acogió parcialmente la excepción de prescripción extintiva, ya que, en su parecer, la acción de la demandante en representación de su hijo estaba prescrita y, además, consideró que, al ser de corto plazo, no admite suspensión. Sobre la falta de legitimación pasiva, el Juzgado consideró que, de acuerdo a la Ley, si bien el Hospital es autogestionado, aquello no conlleva un cambio en la legitimación pasiva, la cual sigue estando radicada en el Servicio de Salud.

Luego, sobre la falta de servicio, el Juzgado consideró el testimonio de un médico cirujano debidamente juramentado y no tachado, que indicó que lo recomendable era haber practicado la cesárea. Junto con ello, consideró que la demandante fue diagnosticada con diabetes gestacional una semana antes de dar a luz y no se le practicó una ecografía para determinar el tamaño del feto, ni tampoco detectaron la macrosomía de este. El mismo hospital tiene un protocolo sobre "desproporción céfalo pélvica" y la Guía Perinatal de 2015, emitida por el Ministerio de Salud, reconoce la macrosomía fetal como una desproporción, de manera que, la lex artis, aconsejaba la práctica de una cesárea, configurándose la falta o culpa del servicio, concediéndose una indemnización del daño moral por la suma de $\$ 30.000 .000$.

La parte demandada apeló de esta sentencia para ante la Corte de Apelaciones de Santiago ${ }^{2}$, apelación a la que se adhirió la demandante. En cuanto a la adhesión, la demandante indica, que el monto del daño moral no se condice con los daños ocasionados. La Corte de Apelaciones, expuso que la pérdida de agrado o goce, la frustración de expectativas legítimas, el daño estético íntimo, y las secuelas de orinar por el ano y defecar por la vagina, alteran su vida familiar, y no se ha podido determinar si esos daños podrán repararse, de manera que, concedió una indemnización por $\$ 100.000 .000$. En cuanto a la apelación de la demandada, indica que sus argumentaciones no logran desvirtuar lo decidido, de manera que, se confirma la sentencia con declaración del aumento en el monto a indemnizar por concepto de daño moral.

En contra de esta última decisión, la parte demandada dedujo recurso de casación en el fondo. La Corte Suprema ${ }^{3}$, al conocer del recurso, consideró que resultó suficientemente acreditada la concurrencia de la falta de servicio, ya que, diagnosticó la diabetes gestacional pero no se hizo ecografía para determinar el tamaño del feto. Tampoco detectaron la macrosomía, por lo que la lex artis aconsejaba una cesárea, sin embargo, al no emplearse, hubo falta de cuidado del personal médico, por lo que la conclusión de los falladores resulta suficientemente fundada. Además, declaró que la acción interpuesta por la demandante no estaba prescrita y que esta sufrió un perjuicio sexual, que consiste en la imposibilidad absoluta o durante un periodo más o menos prolongado de tiempo para hacer vida sexual normal a consecuencia de lesiones físicas.

\section{Daño moral y daño no patrimonial}

La historia de la reparación del daño moral en Chile, no ha sido la misma para el ámbito contractual y extracontractual de responsabilidad. De acuerdo a Barros, en materia de responsabilidad contractual, el Código Civil, en su artículo 1556, se limita a clasificar tan solo los daños patrimoniales ${ }^{4}$. Por ello, según el mismo autor, aquella norma "fue tenida por una barrera insalvable para la reparación del daño moral, porque sólo da lugar a la indemnización del daño emergente y del lucro cesante. Por el contrario, una lectura literal del artículo 2329 permitía inferir que en sede extracontractual no regía esa limitación" ${ }^{5}$.

\footnotetext{
${ }^{2}$ Corte de Apelaciones de Santiago, Rol № 12.796-2017, de 14 de septiembre de 2018.

${ }^{3}$ Corte Suprema, Rol № 33.598-2018, de 30 de abril de 2020.

${ }^{4}$ BARROS (2006), p. 220.

${ }^{5}$ BARROS (2006), p. 341.
} 
Domínguez, indica que la regulación del daño moral en sede contractual "ha estado entregada a la labor jurisprudencial" ${ }^{6}$, desde donde se han elaborado argumentos para admitir esta partida indemnizatoria en sede contractual. Barros, indica que "la jurisprudencia ha seguido diversas estrategias. Ante todo, ha afirmado que la norma del artículo 1556 no debe entenderse como excluyente del daño moral, porque no contendría una enumeración exhaustiva de los daños indemnizables" 7 . Por tanto, a partir del silencio del artículo 1556, se ha construido el argumento que admite la reparación del daño moral en sede contractual.

Para el caso de la responsabilidad extracontractual, Domínguez indica que, la admisión de la reparación de atentados extrapatrimoniales se da a partir de una reinterpretación de los artículos 2314 y $2329^{8}$, coincidiendo con lo manifestado por Barros en torno al artículo 2329.

Por ello, la admisibilidad de la reparación del daño moral en el ordenamiento jurídico chileno, se daría en sede contractual ${ }^{9}$ por una interpretación amplia del artículo 1556 , y en sede extracontractual por la interpretación de los artículos 2314 y 2329, todos del Código Civil.

De allí, a su vez, se desprendería un reconocimiento al principio de reparación integral del daño, puesto que, como indica Domínguez, se reconocería "en toda su amplitud y entidad, la reparación de todos los daños patrimoniales y no patrimoniales, sin distinción y en cualquier ámbito de la misma. Puede afirmarse entones que, en Chile, el principio de reparación integral recibe hoy amplio reconocimiento" ${ }^{10}$.

Si bien hoy existe claridad en cuanto al reconocimiento, tanto normativo como jurisprudencial, del daño moral tanto en el ámbito contractual como extracontractual, no existe tanta claridad en torno a su contenido.

Barros ha manifestado que "La dificultad de expresar el alcance y contenido del daño se muestra en la diversidad de denominaciones en las principales tradiciones jurídicas" ${ }^{11}$ y que, "En rigor, solo las lesiones a bienes de la personalidad constituyen un daño propiamente moral (entendido como lo concerniente al fuero interno o al respeto humano); no lo son, por el contrario, el dolor corporal, la angustia psicológica o la pérdida de oportunidades para disfrutar de una buena vida, que, sin embargo, se entienden inequívocamente pertenecientes a esa categoría" ${ }^{12}$. Es decir, de acuerdo al autor, si bien un daño estrictamente moral es tan solo aquel que afecta bienes de la personalidad, necesariamente hemos debido considerar que otro tipo de daños también son morales, aunque no respondan estrictamente a un daño moral.

Este problema conceptual ha sido abordado también por Diez-Picazo, quien ha manifestado que el daño moral corresponde a una figura borrosa ${ }^{13}$ y que en torno a él "el problema parece ser doble: por una parte, la necesidad de delimitar lo más precisamente posible el concepto de daño moral y, por otra, es preciso averiguar en qué casos resulta indemnizable y con arreglo a qué criterios" ${ }^{14}$.

Pese a la borrosa delimitación del concepto, Diez-Picazo ha formulado una definición, al menos tentativa, de daño moral bajo esa denominación, manifestando que "hay un concepto estricto de daño moral que arranca de la vieja idea de pretium doloris y que se ha definido como dolor, sufrimiento, padecimiento psíquico o físico injustamente ocasionado o, según la expresión de Scognamiglio, dolores y padecimientos de ánimo que integran el reflejo subjetivo del daño injusto" ${ }^{15}$.

En virtud de lo expresado, existe doctrina nacional que ha propuesto modificar la nomenclatura con la que se desarrolla este rubro indemnizable y reemplazarlo, más bien, por el de daño no patrimonial. Así, Domínguez propone el abandono de la concepción clásica que

\footnotetext{
${ }^{6}$ DOMÍNGUEZ (2006a), p. 229.

${ }^{7}$ BARROS (2006), p. 341.

8 DOMÍNGUEZ (2006a), p. 229; DOMÍNGUEZ (1999), p. 32.

${ }^{9}$ Ver más en DE LA MAZA (2018), pp. 275-309.

10 DOMÍNGUEZ (2006a), p. 243.

${ }^{11}$ BARROS (2006), p. 287.

12 BARROS (2006), p. 287.

13 DÍEZ-PICAZO (1999), p. 324.

${ }^{14}$ DIEZ-PICAZO (1999), p. 325.

15 DIEZ-PICAZO (1999), p. 326.
} 
asocia el daño moral con el pretium doloris, ya que, el daño moral se refiere "más bien a una categoría de perjuicios que precisamente tienen en común su carácter no patrimonial" 16 .

En una línea similar, Barros indica que el daño moral tiene otra cara, a la que muy genéricamente se le denomina perjuicio de agrado ${ }^{17}$, el que puede contemplar incontables tipificaciones y subdivisiones, ya que, "son innumerables y disímiles las ventajas de la vida que una persona pueda disfrutar y las actividades que puede desarrollar en el ámbito deportivo, artístico o en la vida de relación, incluyendo la vida sexual y familiar"18.

Si bien todo esto ya es lo suficientemente complejo, desde el punto de vista terminológico y conceptual, Diez-Picazo indica que existe doctrina que asocia el daño moral a aquel que deriva de ataques a la integridad física, al que denominan daño corporal, y que dentro de aquel concepto incluyen "1. Los sufrimientos morales y psíquicos, que comprenden las mismas ideas que la vieja idea pretium doloris; 2. El perjuicio estético (prix de la beauté, pretium pulchritudinis). 3.o El denominado "perjuicio sexual», que comprende la imposibilidad total o parcial para la víctima de mantener relaciones sexuales o de procrear. 4. El daño a la que podríamos denominar vida de relación (préjudice d'agrément)"19.

Pues bien, no existe uniformidad en torno a la tipificación de daños morales, ni las subdivisiones que puedan existir entre ellos, ni cómo distinguirlos unos de otros. Las fronteras entre diversos conceptos que pueden ser englobados dentro del concepto de daño moral o daño no patrimonial no son uniformes, nítidas, ni bien definidas.

No pretendo dirimir cual es la forma correcta de ordenar toda esta evidente dispersión conceptual. Para efectos de este trabajo tan solo me interesa rescatar que los autores citados reconocen la existencia del perjuicio sexual como un rubro indemnizable de daños, y que, si este ha de ser indemnizado, corresponde catalogarlo como un daño moral, no patrimonial o extrapatrimonial.

\section{Perjuicio Sexual}

Al igual que con el concepto de daño moral, el concepto de perjuicio sexual no se encuentra claramente definido. Sin embargo, puede recurrirse a los esfuerzos jurisprudenciales y doctrinales en torno a él.

En el ámbito nacional, puede partirse indicando que la Corte Suprema manifestó que el perjuicio sexual "consiste en la imposibilidad absoluta o durante un periodo más o menos prolongado de tiempo para hacer vida sexual normal a consecuencia de lesiones físicas" ${ }^{20}$. La Corte, manifestó que esa es la definición dada por Carmen Domínguez en un texto publicado en la Revista de Derecho de la Universidad Católica del Norte, en el año 1999. Sin embargo, en dicho texto, la autora manifiesta que este está "referido a la imposibilidad moral que tiene la víctima para llevar una vida sexual normal como consecuencia del atentado. Incluso comprende la pérdida de esa vida sexual derivada de la pérdida de deseo de su cónyuge a causa de la invalidez que ésta sufre" ${ }^{21}$, no precisando expresamente que dicho atentado corresponda necesariamente a lesiones físicas.

Por su parte, Barros incluye el perjuicio sexual dentro del perjuicio de agrado, el cual, según él "Consiste en la privación de agrados normales de la vida; en la pérdida de la oportunidad de disfrutar de aspectos importantes de la existencia. Son típicamente perjuicios de este orden la incapacidad para el desplazamiento y la entretención, para la lectura o la audición, para una actividad sexual normal y la procreación" 22 .

\footnotetext{
${ }^{16}$ DOMÍNGUEZ (2006b), p. 289.

17 BARROS (2006), p. 291.

${ }^{18}$ BARROS (2006), p. 291.

${ }^{19}$ DIEZ-PICAZO (1999), p. 327.

${ }^{20}$ Corte Suprema, Rol № 33.598-2018, de 30 de abril de 2020.

${ }^{21}$ DOMÍNGUEZ (1999), p. 35.

${ }^{22}$ BARROS (2006), p. 324.
} 
En España, como se indicó anteriormente, Diez-Picazo al tratar este aspecto, manifestó que cierta doctrina considera al perjuicio sexual como "la imposibilidad total o parcial para la víctima de mantener relaciones sexuales o de procrear" ${ }^{23}$. Eduardo Murcia, por su parte, manifiesta que "La Dra. Criado del Río señala que tanto puede encuadrase en los daños morales como dentro del hándicap afectivo-familiar y hace un interesante análisis señalando sus diversas consecuencias: 1 . Sobre la función reproductora y capacidad para la relación sexual (aspecto anatomo-funcional), que considera integrado en el daño psicofisiológico-funcional. 2. En la esfera psíquica, por el sufrimiento moral debido a la imposibilidad de procrear o de tener relaciones sexuales satisfactorias. 3. En la disminución de la capacidad de atracción, englobándolo en el daño estético. 4. En las repercusiones patrimoniales como podrían darse en aquellas personas cuya actividad lucrativa se basa en algún tipo de comercio sexual actividades que, aunque estén reprobadas, no son delictivas. 5. Y, por último, el daño derivado de la pérdida o disminución del placer sexual o disfrute de la vida sexual que es el que directamente hace corresponder con el daño o perjuicio sexual" 24 .

En Francia, Thierry Papart ha manifestado que, "En 1977, la Dra. Melennec formuló una primera definición: Imposibilidad total o parcial para la víctima, debido a las secuelas traumáticas, de realizar el acto sexual o de procrear o reproducirse de manera normal" 25 . Acto seguido, el mismo autor indica que "J.-L. Fagnart completó esta definición binaria evocando los cuatro aspectos del perjuicio sexual: - la genitalidad, que es la capacidad de realizar el acto sexual (un conjunto de fenómenos fisiológicos localizados en los órganos genitales durante la relación sexual); - La sexualidad, que incluye el deseo (libido) y el placer (que va desde el placer sensual hasta el orgasmo); - La afectividad, que se suele llamar "amor» (una relación en la que el otro es objeto de deseo y placer, pero es en sí mismo objeto de deseo y acción); - La procreación (si la actividad sexual resulta en placer sexual, también tiene como propósito principal la reproducción de la especie)" 26 .

Tanto en Chile como en la doctrina extranjera, se define de forma general, que el perjuicio sexual es aquel que impide mantener sexuales normales o procrear. De dicha definición, no parece restringirse que el origen del mismo sean necesariamente lesiones corporales. Por tanto, la definición utilizada por la Corte Suprema, es más restrictiva que aquella dada por la doctrina.

En lo que respecta a los ámbitos o aspectos de la vida íntima que se ven afectados por un perjuicio sexual, en Chile no existe demasiado desarrollo. Sin embargo, en la doctrina española y francesa, se expresa que las consecuencias de este tipo de daño pueden abarcar la esfera psíquica, afectiva, sexual, reproductiva, inclusive estética y patrimonial. Es decir, a producto del daño, pueden verse afectados distintos aspectos de la vida íntima de la víctima, que le impidan mantener relaciones sexuales o una vida sexual normal.

Tanto en Chile, como en España y en Francia, se vincula el perjuicio sexual con la noción de relaciones sexuales normales. Estas últimas, se han definido como "el contacto físico entre personas fundamentalmente con el objeto de dar y/o recibir placer sexual, o con fines reproductivos. La relación sexual abarca muchas posibles actividades o formas de relación entre dos personas y no se limita sólo a coito o penetración. Incluye, en general, cualquier contacto que suponga excitación sexual con o sin orgasmo, como abrazos, masajes, caricias o besos en el cuerpo pero no en los genitales, caricias en la zona genital, sexo oral y penetración (con o sin eyaculación dentro de la vagina)" ${ }^{27}$. De manera tal que, el impedimento total o parcial, o la relación sexual normal, debiese evaluarse, no tan solo desde un punto de vista reproductivo, ni tan solo enfocado en el coito, sino teniendo en consideración todas las posibles actividades que puedan desplegar los intervinientes para lograr la excitación sexual. En otros términos, es posible que un atentado no afecte la capacidad reproductiva de la víctima, por ejemplo, pero aquello no quiere decir que el perjuicio sexual no exista.

\footnotetext{
23 DIEZ-PICAZO (1999), p. 327.

${ }^{24}$ MURCIA (2002), p. 161.

${ }^{25}$ PAPART (2006), p. 61.

26 PAPART (2006), pp. 61-62.

27 MENDOZA et al. (2016), p. 244.
} 
Atendido aquello, es posible distinguir entre, a lo menos, dos tipos de perjuicio sexual. Uno, será aquel originado en una lesión corporal, cuya consecuencia principal será la inhabilidad o dificultad para el coito y la procreación. Aquí se encuadra el caso en comento, o, por ejemplo, el caso de una intervención médica a una mujer, en virtud de la cual suturaron su útero, esterilizándola sin su consentimiento ${ }^{28}$. Por otra parte, estará el perjuicio sexual originado en un evento traumático que provoque secuelas psicológicas, las cuales pueden dificultar las demás posibles actividades destinadas a la excitación sexual. Aquí se encuadran los delitos sexuales. En palabras de Murcia "podríamos clasificar los perjuicios sexuales como derivados de daños físicos (lesiones o secuelas anatómicas o funcionales) o psíquicos (alteraciones de la salud mental)" 29.

Sobre estos últimos, de acuerdo al mismo autor, "de todas las posibles consecuencias sobre la víctima que puede tener un delito contra la libertad sexual, la repercusión psíquica se dará siempre. Las lesiones físicas pueden faltar en algunos delitos de esta naturaleza pero las consecuencias emocionales y psicológicas nunca faltarán" ${ }^{30}$.

De acuerdo a Rodríguez, dentro de estos delitos se encuentran aquellos que "se orientan hacia la protección de intereses individuales, entre los que cabe mencionar los delitos de violación, estupro y abuso sexual" ${ }^{31}$. El mismo autor indica que, su "objeto de tutela es el derecho de las personas a no verse involucradas en un contexto sexual, en atención al daño físico, psíquico o emocional- que tal experiencia puede ocasionar en el común de los seres humanos" 32 .

Estas secuelas psíquicas o emocionales han sido abordadas por determinadas áreas de la salud como la psicología y psiquiatría. González y Pardo, han manifestado que la agresión sexual es un delito altamente estresante para la víctima, quien lo vivencia con miedo a sufrir un grave daño físico o incluso la muerte, del cual deriva un impacto psíquico, cuyas repercusiones pueden manifestarse con inmediatez al trauma o diferido en el tiempo ${ }^{33}$. Indican que el trastorno por estrés postraumático ${ }^{34}$ es la nosología que con mayor frecuencia aparece tras una agresión sexual $^{35}$ y que su forma compleja presenta "sexualidad compulsiva o extremadamente inhibida" ${ }^{36}$. Gisbert, agrega "fobias, rechazo a la sexualidad, lavarse de modo compulsivo y vómitos de repetición en caso de felaciones impuestas" ${ }^{37}$.

Junto con este trastorno, González y Pardo indican que una agresión sexual puede producir disfunciones sexuales, tales como disminución del deseo, evitación de las relaciones sexuales, y evocaciones de recuerdos de la agresión durante sus relaciones normales, síntoma que, según ellos, aparece hasta en un $12 \%$ de las víctimas ${ }^{38}$.

Por tanto, no cabe duda, a nivel médico, que los delitos sexuales pueden provocar graves repercusiones de índole psíquica y psicológica en las victimas, las que indiscutidamente afectan la capacidad de aquella de mantener relaciones sexuales normales con posterioridad a la consumación del delito. Dicho daño, también corresponde ser indemnizado.

La jurisprudencia nacional, ya ha tenido que enfrentarse a la existencia de secuelas psicológicas en víctimas de delitos sexuales. Así, en un caso sobre trata de personas con fines de explotación sexual, en carácter de reiterado, el Cuarto Tribunal de Juicio Oral en lo Penal de Santiago ${ }^{39}$, dictó sentencia en la causa civil interpuesta en el proceso penal correspondiente, acogiendo la solicitud de indemnización de perjuicios en contra de los acusados, quienes fueron condenados solidariamente a indemnizar a las víctimas por el daño moral causado.

\footnotetext{
${ }^{28}$ Corte Suprema, Rol № 9058-2015, de 03 de septiembre de 2015.

${ }^{29}$ MURCIA (2002), p. 166.

${ }^{30}$ MURCIA (2002), p. 167.

${ }^{31}$ RODRÍGUEZ (2000), p. 123.

32 RODRÍGUEZ (2000), pp. 123-124.

${ }^{33}$ GONZÁLEZ Y PARDO (2007).

${ }^{34}$ Ver más en AMOR et al. (2001), pp. 605-629.

${ }^{35}$ GONZÁLEZ Y PARDO (2007).

${ }^{36}$ GONZÁLEZ Y PARDO (2007).

37 GISBERT (2002), p. 109.

38 GONZÁLEZ Y PARDO (2007).

${ }^{39} 4$ o Tribunal de Juicio Oral en lo Penal de Santiago, Rit № 293-2013, de 02 de noviembre de 2013.
} 
En el curso de la investigación penal, las víctimas fueron evaluadas por una psicóloga perito quien manifestó que una de las víctimas presentó estrés postraumático crónico, alteración del curso de su sexualidad, entre otras repercusiones. La especialista indicó que esto "podría generar desconfianza y afectar la sexualidad de pareja futura sobre todo si sabe lo que pasó".

Luego, para efectos de la demanda civil, el Tribunal consideró la explicación de otra psiquiatra respecto de la misma víctima. La especialista indicó que esta "presenta una sintomatología post traumática, que se produce a partir de un trauma, que puede ser provocado por variadas situaciones, tales como violencia física o violencia sexual".

Si bien es cierto que el Tribunal no habla exactamente de perjuicio sexual, aborda el daño moral desde los daños psicológicos derivados de violencia sexual, la que, de acuerdo a las especialistas, puede provocar alteración del curso de la sexualidad y afectar la sexualidad con una pareja futura, repercusiones que, de acuerdo a lo expresado anteriormente, corresponden a perjuicio sexual.

Cabe destacar que, tanto en el caso en comento como en el caso del delito de trata de personas, los respectivos tribunales repararon en la juventud de las víctimas para evaluar el perjuicio sexual. En el caso en comento, la Corte Suprema manifestó que, al tener 33 años de edad, la víctima vio frustrados "todos sus proyectos de vida, incluida su vida afectiva y sexual". Sin embargo, la edad como factor para evaluar la existencia del perjuicio sexual debe ponerse en entredicho, ya que, de acuerdo a Mendoza y otros especialistas, los humanos desarrollan y exploran su sexualidad durante toda la vida ${ }^{40} y$, según Herrera, inclusive hasta adentrados en la tercera edad ${ }^{41}$. Por tanto, no puede concluirse que mientras mayor la víctima, menor el perjuicio sexual, salvo en casos que se relacionen con la capacidad reproductiva, la cual de acuerdo a Acuña y otros, difícilmente podrá concretarse luego de los 52 años de edad ${ }^{42}$. En casos de delitos sexuales, por otra parte, puede producirse el trastorno de estrés postraumático en cualquier etapa de la vida humana, produciendo disfunción sexual a cualquier edad ${ }^{43}$.

En suma, el perjuicio sexual puede derivar de lesiones fisiológicas en la víctima, o de lesiones emocionales psicológicas, las que, de acuerdo a Murcia, se darían siempre en casos de delitos sexuales. El perjuicio sexual, abarca distintos ámbitos de la vida íntima de la víctima, desde el aspecto afectivo hasta el reproductivo, lo cual debe ser debidamente identificado para cada caso. De allí se extrae claramente la utilidad de recurrir al concepto de perjuicio sexual, ya que, existen casos en que el tratamiento del daño moral implica necesariamente analizar la vida sexual y afectiva futura de la víctima y sus deseos reproductivos, o los traumas sexuales psicológicos que pueden generarse como secuela de un delito. Por tanto, el análisis del perjuicio sexual permite abordar el daño extrapatrimonial de forma más precisa al momento de identificar su existencia, pudiendo, inclusive, identificar cuál es el aspecto de la vida íntima de la víctima que se verá afectado por el hecho dañoso, y desde allí, evaluar con precisión la existencia, o no, de dicho daño extrapatrimonial.

\section{Perjuicio sexual y obligaciones matrimoniales}

Despejado lo que es un perjuicio sexual, corresponde responder si del hecho de que uno de los cónyuges no pueda procrear o mantener relaciones sexuales, en virtud de un perjuicio sexual, implica que está infringiendo los deberes del matrimonio, principalmente el de cohabitación.

Primero, debe indicarse que de acuerdo al artículo 102 del Código Civil, que define el matrimonio, uno de los fines de este es la procreación. De manera tal que si a producto de un

\footnotetext{
${ }^{40}$ MENDOZA et al. (2016), p. 244.

${ }^{41}$ Ver más sobre sexualidad en la vejez en HERRERA (2003), pp. 150-162.

${ }^{42}$ ACUÑA et al. (2013), p. 358.

${ }^{43}$ Ver más sobre disfunciones sexuales de origen psicológico en SELL Y PADRÓN (2001), pp. 115-123; en SÁNCHEZ et al. (2005), pp. 74-

80; y en POMEROL (2010), pp. 599-602.
} 
perjuicio sexual, derivado de daño corporal, uno de los cónyuges queda inhabilitado para procrear, no podría cumplirse con este fin.

Segundo, en opinión de Ramos Pazos, el deber de cohabitación es la "obligación que tienen los cónyuges de mantener relaciones sexuales entre sí. El incumplimiento de este deber puede llegar a constituir una causal para mantener la separación judicial (art. 26 inciso 1ㅇ) y el divorcio (art. 54 № 2)" ${ }^{\prime 4}$, ambos de la Ley de Matrimonio Civil ${ }^{45}$, de manera que, si uno de los cónyuges se niega a mantener relaciones sexuales, entonces infringiría este deber.

Sin embargo, esta infracción tan solo tiene relevancia para efectos de la solicitud de divorcio por parte del cónyuge no infractor. Sobre aquello Ramos Pazos expresa que "Como es sabido, respecto a las causales de divorcio, la doctrina y la legislación comparada se mueven entre dos polos: "divorcio-sanción" y "divorcio remedio" (llamado también "divorcio solución"). El primero está concebido como una pena para el cónyuge culpable de una conducta que lesiona gravemente la vida familiar. En el segundo, en cambio, el divorcio se acepta como la solución a una crisis proveniente de la ruptura definitiva de la armonía conyugal, cuando la convivencia de la pareja se torna imposible" ${ }^{46}$.

Siguiendo esa línea, el autor citado indica que "El artículo 54 establece que 'el divorcio podrá ser demandado por uno de los cónyuges, por falta imputable al otro, siempre que constituya una violación grave de los deberes y obligaciones que les impone el matrimonio, o de los deberes y obligaciones para con los hijos, que torne intolerable la vida en común"' 47 , aquello implica que para demandar el divorcio culpable debe haber infracción imputable, y en el caso de la infracción de deberes matrimoniales como consecuencia de un perjuicio sexual, la infracción no es imputable al cónyuge víctima de dicho perjuicio. Su imposibilidad, ya sea física o emocional, de cohabitar o procrear, deriva de un daño anterior.

De hecho, en este tipo de casos se puede hacer aplicable el deber de ayuda mutua o de asistencia que deriva del artículo 131 del Código Civil en favor del cónyuge víctima de un perjuicio sexual, el cual, según Ramos "Consiste en los cuidados personales y constantes que los cónyuges se deben recíprocamente. Como dice un autor, este deber abarca todo lo que pudiéramos llamar el lado negativo de la vida: miserias, desgracias, enfermedades'”48.

En suma, si uno de los cónyuges ha sido víctima de un perjuicio sexual, y en virtud de aquel queda impedido para mantener relaciones sexuales o procrear, no puede decirse que está infringiendo sus deberes matrimoniales de forma imputable, de manera que el otro de los cónyuges no puede demandar el divorcio culposo e inclusive, puede hacerse aplicable que aquel cónyuge, ayude y asista emocionalmente al cónyuge víctima y no lo deje en el abandono soportando los infortunios de su dolor físico, psíquico y emocional, según sea el caso.

\section{6. ¿Perjuicio sexual por rebote?}

Todo lo manifestado hasta aquí, es aplicable para la víctima directa del daño, es decir, para la víctima que sufre el perjuicio sexual derivado de lesiones corporales o fisiológicas y también emocionales, en su propio cuerpo, que le impiden mantener relaciones sexuales normales. Pero junto a ellos, están los lesionados indirectos, victimas por rebote o repercusión. Se ha dicho que "Los lesionado indirectos son aquellos que reciben un daño, no directamente a su persona o bienes, sino por sufrir ellos las consecuencias de un daño causado a una persona con la cual tienen alguna relación. A su vez los lesionados indirectos pueden reclamar daño patrimonial o daño moral" 49 .

Sin entrar en profundidad en la identificación de quienes están legitimados para demandar un daño como víctimas por rebote, se ha dicho que, "En principio, todas aquellas

\footnotetext{
${ }^{44}$ RAMOS (2007a), p. 148.

${ }^{45}$ Ley № 19.947, de 2004.

${ }^{46}$ RAMOS (2007a), pp. 105-106.

${ }^{47}$ RAMOS (2007a), pp. 106-107.

${ }^{48}$ RAMOS (2007a), p. 145.

${ }^{49}$ CORRAL (2013), pp. 353-354.
} 
personas que por la muerte o lesión de la víctima directa sufran un perjuicio moral estarán habilitadas para solicitar su reparación" 50 .

Pues bien, sin que este sea un examen profundo y acucioso, en caso de admitir la existencia de un perjuicio sexual por rebote, en principio los que principalmente deberían estar legitimados para demandarlo son el cónyuge o el conviviente civil de la víctima directa del daño. Ellos demandarían su perjuicio sexual personal, puesto que, en principio, si su cónyuge o conviviente civil no puede mantener relaciones sexuales normales, por repercusión, ellos tampoco, al menos no con ella. Ellos se verían perjudicados sexualmente, ya que la víctima directa del daño puede desarrollar disminución, desinterés, desconfianza o disfunción sexual. Inclusive, si el daño a la víctima directa le impide la procreación, el cónyuge o el conviviente civil se verían impedidos, a su vez, de procrear mediante relaciones sexuales con ella, lo que podría conllevar, como indica Barros, un "deterioro del normal desarrollo de la vida familiar, afectiva o sexual" 51 .

Podría incluirse también como víctima por rebote de un perjuicio sexual, al concubino o concubina. Ramos citando a Federico Puig indica que el concubinato es "la unión duradera y estable de dos personas de sexo opuesto, que hacen vida marital con todas las apariencias de un matrimonio legítimo" ${ }^{52}$. Junto con aquello, el autor manifiesta que "Lo que caracteriza al concubinato es el hecho de que la pareja mantenga relaciones sexuales fuera del matrimonio, con cierto grado de estabilidad y duración, realizando un género de vida semejante a las unidas por vínculo matrimonial" ${ }^{53}$.

Luego, existe la distinción entre el concubinato perfecto e imperfecto dependiendo de si existe una vida en común bajo un mismo techo y que sea públicamente conocida, o si por el contrario la relación es clandestina ${ }^{54}$, aunque de todas formas, Ramos indica que "la publicidad de la relación no es elemento del concubinato" 55 y que "no es requisito del concubinato que la pareja viva bajo el mismo techo ${ }^{56}$.

Atendido aquello, existen buenas razones para considerar que el concubino o concubina también puede sufrir un perjuicio sexual por rebote, puesto que, existe estabilidad y duración en las relaciones sexuales y existe una forma de vida similar a la que genera el matrimonio, como si estuvieran casados sin estarlo ${ }^{57}$. Es cierto que, más discutible podría resultar la indemnización a los concubinos que vivan bajo la forma del concubinato imperfecto, es decir, que no vivan bajo un mismo techo y que su relación sea clandestina. Con todo, la Corte Suprema ha manifestado que "se reconoce hoy legitimación para la reparación de perjuicios en caso de muerte de concubinos" 58 , de manera que no sería del todo imposible aceptar, así mismo, la reparación de su perjuicio sexual por rebote.

Sin embargo, debe discutirse seriamente la procedencia de este tipo de perjuicio por repercusión. Barros ha manifestado que "la concesión de una compensación por estos daños reflejos suele proceder únicamente cuando los sufrimientos morales de la víctima por repercusión alcanzan una 'gravedad excepcional', que supere la simple pena de ver sufrir un ser querido" ${ }^{59}$, esto tiene sentido toda vez que la víctima por rebote demanda un daño propio, el que no puede justificarse, tan solo, por la pena de ver a otro sufrir.

Por lo tanto, la gravedad excepcional en caso del perjuicio sexual por rebote, debe argumentarse desde la disfunción sexual dentro de la pareja y la incapacidad de procrear biológicamente entre ellos (dependiendo el caso). Como se indicó, cuando hablamos de victimas

\footnotetext{
${ }^{50}$ CORRAL (2013), p. 354; ELORRIAGA (2006), pp. 301-302.

${ }^{51}$ BARROS (2006), p. 326.

52 RAMOS (2007b), pp. 647-648.

${ }^{53}$ RAMOS (2007b), p. 648.

${ }^{54}$ RAMOS (2007b), p. 650

${ }^{55}$ RAMOS (2007b), p. 650

${ }^{56}$ RAMOS (2007b), p. 650.

${ }^{57}$ En los términos expresados por René Ramos Pazos citando a Vodanovic en RAMOS (2007b), p. 650.

${ }^{58}$ Corte Suprema, Rol № 31.713-2014, de 25 de noviembre de 2015.

${ }^{59}$ BARROS (2006), p. 352.
} 
por repercusión hablamos de victimas que demandan un daño propio ${ }^{60}$, y por ende, el perjuicio sexual alegado por repercusión debe ser el que se sufre personalmente, o en otros términos "No reclaman la reparación de un perjuicio ajeno sino que la compensación del menoscabo propio" ${ }^{61}$. Del fallo de la Corte Suprema, no fluye alguna alegación por parte del cónyuge, conviviente civil o concubino de la demandante, sin embargo, es posible indicar que aquel también sufrió un perjuicio sexual indemnizable.

\section{Conclusiones}

El estudio del daño moral ha conllevado la aparición de diversos tipos de daños que quedan englobados dentro de su concepto, los cuales son de difícil precisión y clasificación. Uno de ellos es el perjuicio sexual, cuya existencia ha sido reconocida por autorizada doctrina como un daño moral o no patrimonial indemnizable civilmente. El perjuicio sexual puede ser entendido como la imposibilidad absoluta o relativa, fisiológica, psicológica o moral, de mantener relaciones sexuales. Estas últimas entendidas en sentido amplio como cualquier contacto físico que tenga por finalidad la excitación sexual, con o sin orgasmo, con o sin fines reproductivos.

El perjuicio sexual puede tener dos orígenes. Uno fisiológico o corporal y otro psicológico o moral. El perjuicio sexual fisiológico ocurre cuando existen lesiones o un atentado corporal a la integridad física de los órganos sexuales y reproductivos, lo que ocurriría, por ejemplo, en caso de una esterilización no consentida, una castración, o como en el caso en comento, un parto negligente. Por otra parte, el perjuicio sexual psicológico ocurre como consecuencia de un hecho que produce un trauma en la víctima, que se caracteriza por la aparición de ciertos síntomas o psicopatologías, como el trastorno por estrés postraumático, el que a su vez puede generar rechazo, desinterés, inhibición y fundamentalmente disfunción sexual, lo que ocurriría, por ejemplo, en casos de delitos sexuales.

Una persona que presente un perjuicio sexual se puede ver impedido de mantener relaciones sexuales y de procrear, los que a su vez son una obligación del matrimonio y un fin del mismo, respectivamente. Mantener relaciones sexuales con el cónyuge corresponde a la obligación de cohabitación, y no cumplirlo puede derivar en un incumplimiento imputable de las obligaciones matrimoniales, lo que habilitaría al cónyuge no infractor a demandar el divorcio culpable. Sin embargo, si el cónyuge infractor infringe su obligación de cohabitar o no puede cumplir con el fin de procreación del matrimonio, como consecuencia de un perjuicio sexual, no puede predicarse que su incumplimiento es imputable, de manera tal que el otro de los cónyuges no podría demandar el divorcio sanción. Es más, el cónyuge no infractor deberá socorrer y asistir emocionalmente a la víctima directa del perjuicio sexual, ya que se haría exigible su obligación de ayuda y asistencia.

Junto con lo anterior, si una persona sufre un perjuicio sexual, ya sea fisiológico o psicológico, y en virtud de aquel no puede mantener relaciones sexuales o no puede procrear, dicha víctima directa no será la única que sufra el perjuicio sexual, sino también su cónyuge, conviviente civil e inclusive su concubino, ya que la disfunción sexual de la víctima directa repercutirá en ellos, quienes a su vez no podrán mantener relaciones sexuales o procrear, al menos no con la víctima directa, lo que se traduce finalmente en una disfunción sexual propia.

Finalmente, el perjuicio sexual puede afectar diversos ámbitos de la vida íntima de quien lo sufre. Estos ámbitos, de acuerdo a la doctrina española y francesa, pueden ser de índole afectiva, psíquica, reproductiva, estética, patrimonial y estrictamente sexual. La identificación del ámbito específico afectado puede resultar útil para efectos de precisar la existencia del daño extrapatrimonial, puesto que, para conceder la indemnización, muchas veces será necesario evaluar los deseos reproductivos de la víctima, o la inhabilidad de realizar actividades de índole sexual con posterioridad al hecho dañoso.

${ }^{60}$ ELORRIAGA (1999), p. 390

${ }^{61}$ ELORRIAGA (1999), p. 392 
De allí se comprueba claramente la utilidad de recurrir al concepto de perjuicio sexual como daño no patrimonial indemnizable, puesto que ayuda a la identificación de los ámbitos íntimos afectados, y a la evaluación precisa de la existencia del daño indemnizable, lo que puede tener gran relevancia al momento de identificar este daño en casos de responsabilidad médica o delitos sexuales, e inclusive para evaluar la existencia de infracciones a deberes matrimoniales, y daños por repercusión.

\section{BIBLIOGRAFÍA CITADA}

acuña R., Gonzalo; Schwarze M., Juan EnRique; Villa V., Sonia y Pommer T., Ricardo (2013): "Edad máxima en la que una mujer puede ser madre con sus propios óvulos. Revisión sistemática", en: Revista Chilena de Obstetricia y Ginecología (Vol. 78, № 5), pp. 357-359.

Amor, Pedro J.; Echeburúa, enrique; Zubizarreta, Irene y Sarasua, Belén (2001): "Perfil psicopatológico diferencial en víctimas de maltrato doméstico y en víctimas de agresiones sexuales", en: Revista Análisis y Modificación de Conducta (Vol. 27, № 114), pp. 605-629.

BARRos Bourie, EnRIQUe (2006): Tratado de Responsabilidad Extracontractual (Santiago, Editorial Jurídica de Chile).

CORRAL TALCIANI, HeRnán (2013): Lecciones de responsabilidad civil extracontractual, 2a edición actualizada (Santiago, Legal Publishing).

De LA MAZA GAZMURI, IÑIGO (2018): "El daño moral en materia contractual: La mirada de la Corte Suprema”, en: Revista Chilena de Derecho (Vol. 45, № 2), pp. 275-309.

Díez-PICAZo Y Ponce De LEÓN, LUIS (1999): Derecho de Daños (Madrid, Editorial Civitas).

Domínguez HidAlgo, CARMEN (1999): “Aspectos modernos de la reparación por daño moral: Contraste entre el derecho chileno y el derecho comparado", en: Revista de Derecho de la Universidad Católica del Norte Sede Coquimbo (№ 6), pp. 29-46.

Dominguez HidAlgo, CARMEN (2006a): "La reparación del daño moral derivado de contrato en el derecho civil chileno: Realidad y límites", en: De la Maza, Iñigo (Ed.), Cuadernos de Análisis Jurídicos, Colección Derecho Privado III, Temas de Contratos (Santiago, Ediciones Universidad Diego Portales), pp. 227-244.

Domínguez Hidalgo, CARMen (2006b): “Hacia una uniformidad y transparencia de la fijación del quantum indemnizatorio por daño moral”, en: Corral Talciani, Hernán y Rodríguez Pinto, María Sara (Coord.), Estudios de Derecho Civil II (Santiago, Legal Publishing), pp. 275-296.

ELORRIAGA DE BONIS, FABIÁN (1999): "Del daño por repercusión o rebote", en: Revista Chilena de Derecho (Vol. 26, № 2), pp. 369-398.

ELORRIAGA DE BONIS, FABIÁN (2006): "Novedades judiciales en torno al daño moral por repercusión”, en: Corral Talciani, Hernán y Rodríguez Pinto, María Sara (Coords.), Estudios de Derecho Civil II (Santiago, Legal Publishing), pp. 297-322.

GISBERT GRIFO, MARINA S. (2002): “Aspectos psiquiátricos en los delitos contra la libertad sexual”, en: Ciencia Forense, Revista Aragonesa de Medicina Legal (№ 4), pp. 107-141.

González Fernandez, JoRge y PARdo Fernandez, EnCAR (2007): “El daño psíquico en las victimas de agresión sexual", en: VIII Congreso Virtual de Psiquiatría, Interpsiquis 2.007. Disponible en: https://www.uv.es/crim/cas/Secuelas.Psiquicas.pdf [visitado el 03 de junio de 2020].

Herrera P., Adela (2003): "Sexualidad en la vejez ¿Mito o realidad?", en: Revista Chilena de Obstetricia y Ginecología (Vol. 68, № 2), pp. 150-162. 
Mendoza tascón, luis Alfonso; Claros Benítez, Diana isabel y Peñaranda Ospina, Claudia Bibiana (2016): "Actividad sexual temprana y embarazo en la adolescencia: estado del arte", en: Revista Chilena de Obstetricia y Ginecología (Vol. 81, № 3), pp. 243-253.

MURCIA SÁIZ, EdUARDo (2002): “El perjuicio sexual en las víctimas de los delitos contra la libertad sexual", en: Ciencia Forense: Revista Aragonesa de Medicina Legal (№4), pp. 157-170.

PAPART, THIERRY (2006): “Les préjudices particuliers: ... le juste prix?”, en: A.A.V.V., La réparation du dommage. Questions particulières (Louvain-la-Neuve, Editorial Anthemis S.A.), pp. 45-73.

Pomerol Monseny, José María (2010): "Disfunción eréctil de origen psicógeno", en: Archivos Españoles de Urología (Vol. 63, № 8), pp. 599-602.

RAMOS PAZOS, RENÉ (2007a): Derecho de familia, 7ạ edición actualizada (Santiago, Editorial Jurídica de Chile), tomo I.

RAMOS PAZOS, RENÉ (2007b): Derecho de Familia, 7ạ edición actualizada (Santiago, Editorial Jurídica de Chile), tomo II.

Rodríguez CollaO, LUIS (2000): Delitos Sexuales. De conformidad con las modificaciones introducidas por la Ley № 19.617 de 1999 (Santiago, Editorial Jurídica de Chile).

Sánchez Bravo, Claudia; Carreño Meléndez, Jorge; Martínez Ramírez, Susana y Gómez lópez, María EUGENIA (2005): "Disfunciones sexuales femeninas y masculinas: comparación de género en una muestra de la Ciudad de México", en: Revista de Salud Mental (Vol. 28, № 4), pp. 74-80.

Sell LLUVERAS, JoRGe LUIS y PADRón DURÁN, RubÉN S. (2001): “Disfunción sexual eréctil”, en: Revista Cubana de Endocrinología (Vol. 12, № 2), pp. 115-123.

\section{JURISPRUDENCIA CITADA}

Ministerio del Interior con Gilda Melek BarRaza Pinilla (2013): 4ㅇ Tribunal de Juicio Oral en lo Penal de Santiago 02 de noviembre de 2013 (querella criminal y demanda civil en proceso penal), en: Oficina Judicial Virtual.

Aguilera bahamondes Graciela con Servicio de Salud Concepción, Hospital San José de Coronel, I. MUNICIPALIDAD DE CORONEL (2015): Corte Suprema 03 de septiembre de 2015 (recurso de casación en el fondo y en la forma en procedimiento ordinario), en: Oficina Judicial Virtual.

Quiñones Collet Juan Gustavo, Astudillo Ríos Ismelda con EMPReSA de TRANSPortes RuRales (2015): Corte Suprema 25 de noviembre de 2015 (recurso de casación en el fondo en procedimiento ordinario), en: Oficina Judicial Virtual.

Martínez con Servicio de Salud Metropolitano Central (2016): 17ㅇ Juzgado Civil de Santiago 26 de mayo de 2017 (acción de indemnización de perjuicios por responsabilidad extracontractual en procedimiento ordinario), en: Oficina Judicial Virtual.

Martínez con Servicio de Salud Metropoltano Central (2018): Corte de Apelaciones de Santiago 14 de septiembre de 2018 (recurso de apelación de sentencia definitiva en procedimiento ordinario), en: Oficina Judicial Virtual.

Martínez con Servicio de Salud Metropolitano Central (2020): Corte Suprema 30 de abril de 2020 (recurso de casación en el fondo en procedimiento ordinario), en: Oficina Judicial Virtual.

\section{NORMAS JURÍDICAS CITADAS}

Código CIVIL DE CHILE.

LEY № 19.947, establece nueva ley de matrimonio civil. Diario Oficial, 17 de mayo de 2004. 